\title{
Providential Tides: the Double Low Water of Narragansett Bay
}

\author{
D. G. Bowers ${ }^{1}$ (D) J. M. Brubaker ${ }^{2}$
}

Received: 30 March 2020 / Revised: 14 May 2020 / Accepted: 20 May 2020 / Published online: 30 May 2020

(C) The Author(s) 2020

\begin{abstract}
We investigate a mechanism for producing double-lows and double-highs in the semi-diurnal tide by selective amplification of higher harmonics in a resonant gulf. A double low water is observed at Providence, RI, near the head of Narragansett Bay on days when there is a flattening of the low water tidal curve at Newport, at the mouth of the bay. The flattening is caused by an unusually large quarter-diurnal component to the tide at Newport. The quarter diurnal component has the right phase (a maximum close to the time of the minimum in the semi-diurnal tide) to produce a prolonged flattening of the tidal curve around low water. The natural period of Narragansett Bay (for quarter-wavelength resonance) is close to $4 \mathrm{~h}$ and the quarter diurnal tide is amplified, relative to the semi-diurnal tide, within the bay. The selective amplification of the higher harmonic further prolongs the flattening effect at Providence and, occasionally, is sufficient to create a double low water at the head of the bay from quarter and semidiurnal tides alone. More often, though, a sixth-diurnal harmonic produced within the bay, added to the flattened low water at Providence, creates the double low water. This mechanism of selective amplification of tidal harmonics could be relevant to double tides elsewhere.
\end{abstract}

Keywords Tides $\cdot$ Estuary $\cdot$ Double high water $\cdot$ Selective resonance of harmonics

\section{Introduction}

Double-high and double-low waters in the semi-diurnal tide are an unusual feature of sea level observations. In the case of a double low water, sea level falls to a first low tide, rises for a short while and then falls to a second low water before finally rising to a single high tide. Known cases occur at Portland, Dorset in England and Providence, Rhode Island, in the USA, the latter being the subject of this paper; doubtless, more examples are waiting to be discovered. The analogous phenomenon of a double high water is the mirror image of a double low. The best known example, with a long history of scientific study, is found at Southampton on the south coast of England (Airy 1843; Doodson and Warburg 1941; Pugh 1987).

Communicated by Arnoldo Valle-Levinson

D. G. Bowers

d.g.bowers@bangor.ac.uk

1 School of Ocean Sciences, Bangor University, Menai Bridge, Anglesey LL59 5AB, UK

2 Virginia Institute of Marine Science, William \& Mary, 1370 Greate Road, Gloucester Point, VA 23062-1346, USA
The double low water at Providence in Narragansett Bay, RI, was first recorded as early as 1892 (Harris 1907) and reported by Redfield (1980). Although Redfield's monograph is generally very good at providing physical explanations of tidal phenomena in the area, it does not go into the details of the double low water at Providence. The essential ingredient needed to produce a double high or double low water (or, for brevity's sake, a double tide) is an oscillation in sea level with the right amplitude and phase and with a higher frequency than the semi-diurnal tide. The higher frequency oscillation can be a higher harmonic (also called an overtide) of the main tidal constituents, created by the action of friction or shallow water on the tidal streams, or, in a semi-enclosed sea it can be a seiche produced by the tide itself (Bowers et al. 2013) or by some other mechanism. In order to create a double tide, the phasing must be right. For a double low water, the higherfrequency oscillation must have a peak at the time of, or very close to, the minimum in the semi-diurnal tide. In addition, the amplitude of the oscillation must satisfy the condition (Doodson and Warburg 1941)

$\frac{b}{a}>\frac{1}{n^{2}}$

where $b$ is the amplitude of the higher frequency oscillation, $a$ the amplitude of the semi-diurnal tide and $n$ is the ratio of their 
frequencies. The reason that double tides are so rare is that this condition is difficult to satisfy (although not so difficult as previously thought (Woodworth 2017)). For example, for a quarter diurnal harmonic with $n=2$, the amplitude $b$ must be $1 / 4$ that of the semi-diurnal tide. It is unusual, in the open sea, for higher harmonics to exceed a small percentage of the amplitude of the parent semi-diurnal tide. Furthermore, the ratio of amplitudes has to exceed the critical value by quite a margin to produce a double tide that satisfies a visual inspection. To illustrate this point, we have drawn, in Fig. 1, the tidal curves produced by quarter- and semi-diurnal tides with two values of $b / a$ and perfect phasing for a double low water. A value of $b / a=0.25$ produces a flattening of the tidal curve at low water, but no double tide; the higher $b / a$ ratio of 0.4 creates a clear double low water. We will return to this point later in the text, using these particular values of 0.25 and 0.4 for $b / a$ to illustrate the formation of a clear double tide.

One way to increase the ratio $b / a$ is to reduce the amplitude of the semi-diurnal tide relative to that of the higher harmonic. A good hunting ground for double tides is therefore near an amphidrome in the semi-diurnal tide. Southampton, for example, lies close to the nodal line for the semi-diurnal tide in the English Channel. At Port Ellen in Scotland, the main lunar and solar semi-diurnal tides have about the same amplitude: the semi-diurnal tide becomes very small twice each month and a double high water is formed at these times (Byrne et al. 2017). Alternatively (and this is the possibility we wish to assess in this paper), the $b / a$ ratio can be increased by enhancing the amplitude of the harmonic while maintaining that of the semidiurnal tide at about the same level. When a semi-enclosed sea, or gulf, is forced at the mouth with a regular oscillation in sea level, the oscillation in the gulf is amplified to an extent which depends on how close the period of the oscillation is to the natural period of the gulf (Taylor 1921; Prandle 1991; Friedrichs 2010). If we take a gulf with a resonant period closer to $6 \mathrm{~h}$ than 12 and force it with a semi-diurnal tide and a quarter-diurnal harmonic there will be a greater amplification of the quarter-diurnal oscillation than the semi-diurnal one. The ratio $b / a$ will be increased within the gulf and a double tide could form at the head of the gulf when there is no double tide at the mouth. Our aim in this paper is to investigate the extent to which this selective amplification of a tidal harmonic, or harmonics, leads to the formation of the double low water seen at Providence.

\section{The Study Site and an Example of the Double Low Water}

Narragansett Bay is a partly mixed estuary, of somewhat complicated shape, lying mostly in the state of Rhode Island, USA (Fig. 2). The tide in the bay is predominantly semi-diurnal and behaves as a standing wave (Hicks 1959). The mean depth of the bay is $8.3 \mathrm{~m}$ and the distance from Newport at the mouth to Providence at the head is about $32 \mathrm{~km}$. The resonant period (for quarter wavelength resonance) of a gulf with these dimensions is $3.94 \mathrm{~h}$ (Gordon and Spaulding 1987). Narragansett Bay is close to resonance with oscillations having a period of one-sixth of a day.

Water level data (at intervals of $6 \mathrm{~min}$ ) are available from the National Oceanographic and Atmospheric Administration (NOAA) 'Tides and Currents' website (https://tidesandcurrents.noaa.gov) for a number of sites in the bay. A short record of the tide in February 2015 at Newport and Providence is shown in Fig. 3. The rise and fall of water level is somewhat greater at Providence than at Newport, a result of the amplification of the semi-diurnal tide within the gulf. A double low water is seen at Providence on the 25 th. On this day there is also a noticeable flattening of the tidal curve at Newport, but no double low water at that location. Inspection of longer records shows that the double low
Fig. 1 Illustration of Doodson's criterion. A quarter-diurnal harmonic with amplitude equal to one-quarter of the semi-diurnal tide flattens the tidal curve at low water (dashed curve labeled $b / a=$ 0.25 ). Increasing the ratio to 0.4 creates a clear double low water (solid curve). In both cases in this example, the maximum in the harmonic occurs at the same time as the minimum in the semidiurnal tide

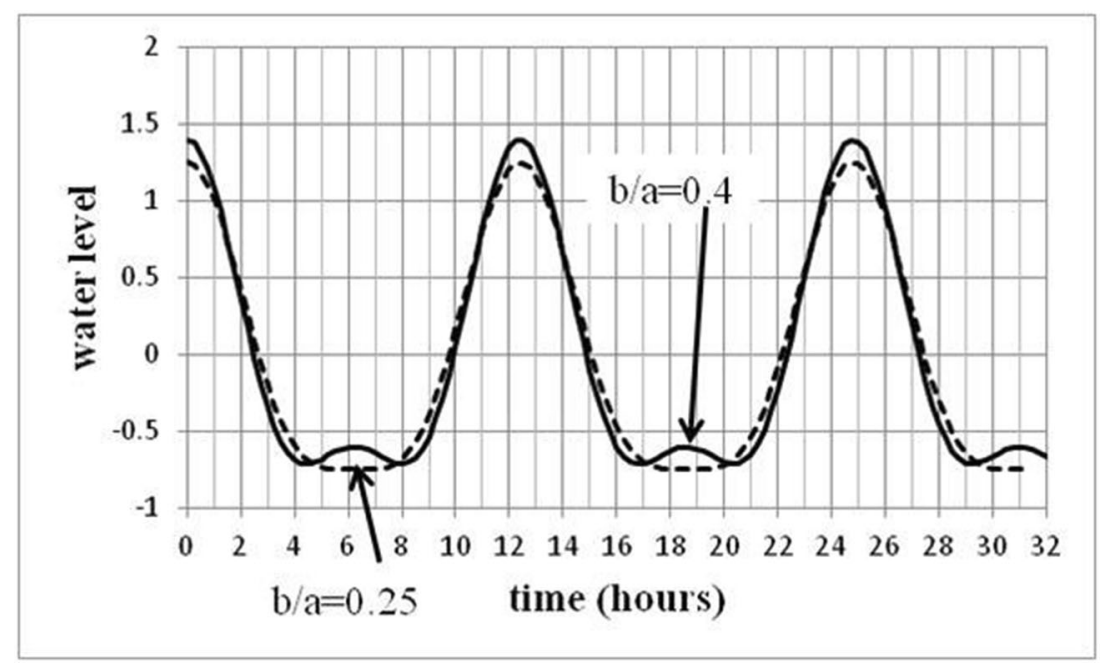




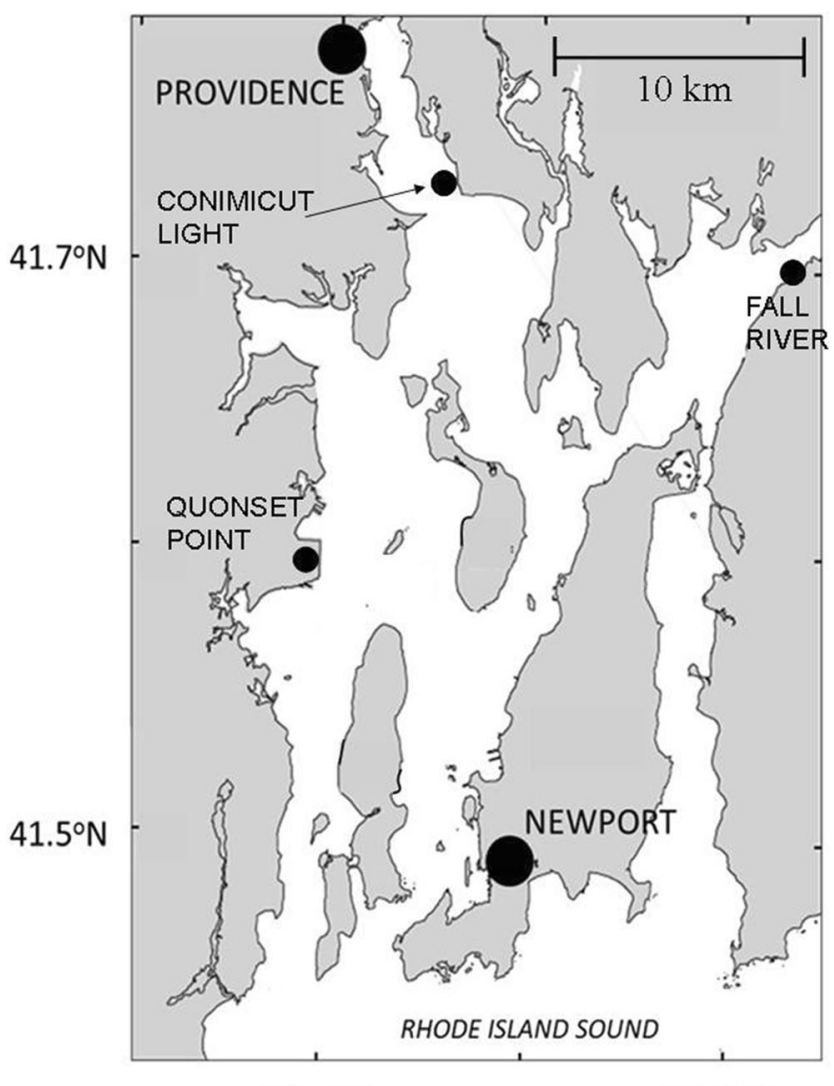

$71.4^{\circ} \mathrm{E}$

Fig. 2 Narragansett Bay, showing the positions of tide gauge stations. This paper is principally concerned with observations at Providence and Newport

water at Providence is always accompanied by a flattening of the low tide at Newport. Double low waters are also seen on the 25th of February at Conimicut Light and Fall River, in the upper parts of the bay, but not at Quonset Point, nearer the mouth at Newport (Fig. 2). The same

observation is true of the double low water seen on 23rd May 2015, which we will come to later.

The amplification factor for a tidal constituent in a gulf, from mouth to head and in the absence of friction, is $1 / \cos (k L)$ (Simpson and Sharples 2012, p85) where $k$ is the wavenumber of the constituent and $L$ the length of the gulf. For Narragansett Bay, the expected amplification from Newport to Providence is 1.14 for a semi-diurnal tide, 1.84 for a quarter-diurnal tide and 13.22 for a sixth-diurnal tide. We would therefore expect the bay to amplify the $b / a$ ratio for quarter to semi-diurnal tides by a factor of $1.84 / 1.14$, or 1.61 (henceforth we will use the symbols $a, b$ and $c$ to represent the amplitudes of the semi-, quarter- and sixth-diurnal components of the tide respectively). If $b / a$ is 0.25 at the mouth of the bay, the selective amplification of the harmonic will increase this ratio to 0.4 at the head and a flattened low tide at Newport should become a double low water at Providence, given that the phase is correct. Selective amplification of the quarter-diurnal tide compared to the semi-diurnal tide, could explain the behavior seen in Fig. 3.

\section{Harmonic Analysis}

The NOAA 'Tides and Currents' website gives the amplitudes of the main tidal constituents at Newport and Providence and a selection of these, relevant to this study, has been reproduced in Table 1. The tide at the mouth is composed of a semidiurnal constituent with amplitude about $0.5 \mathrm{~m}$, a quarter diurnal constituent an order of magnitude smaller and a sixthdiurnal tide an order of magnitude smaller again. The phasing of the quarter-diurnal constituent relative to the semi-diurnal tide is relevant. On average, the high water in the quarter diurnal tide at Newport occurs $0.6 \mathrm{~h}$ after low water in the semi-diurnal tide. This is close to optimal phasing for a double low water (which would require a zero phase difference). Each
Fig. 3 Water level at Newport (dashed line) and Providence (continuous) on 2 days in February 2015. An example of the double low water at Providence is seen at the middle of the day on the 25 th when there is a noticeable flattening of the low tide at Newport

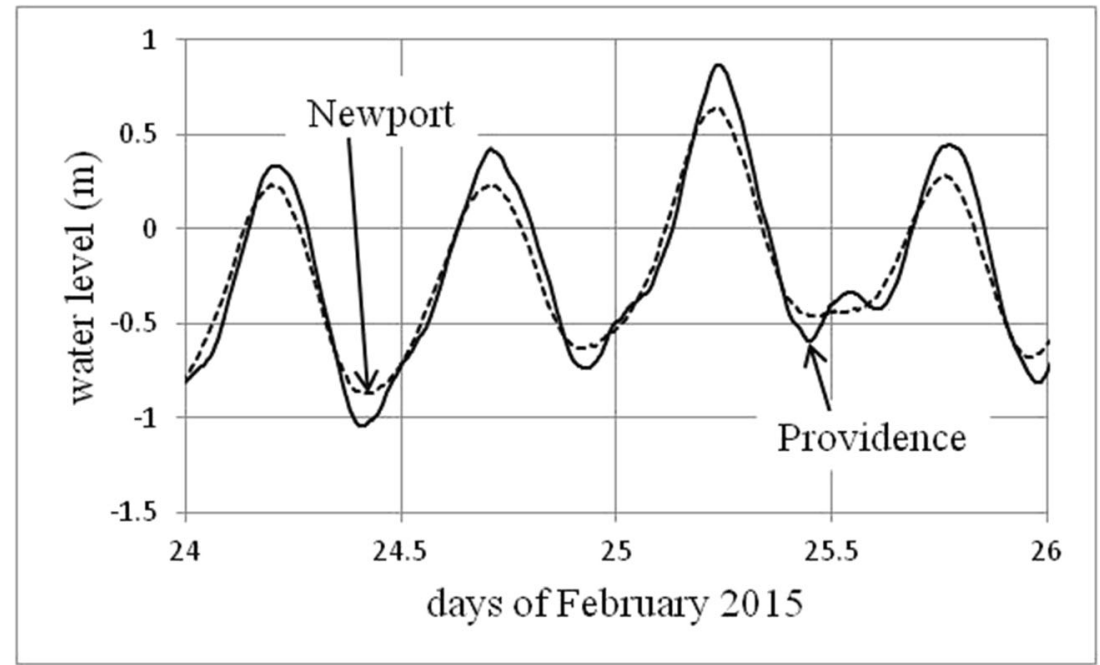


Table 1 NOAA tidal constituent amplitudes at Newport and Providence

\begin{tabular}{lllll}
\hline & Newport & Providence & Observed amplification & Theoretical amplification \\
\hline M2 amplitude, $a(\mathrm{~m})$ & 0.505 & 0.643 & 1.27 & 1.14 \\
M4 amplitude, $b(\mathrm{~m})$ & 0.057 & 0.103 & 1.81 & 1.84 \\
M6 amplitude, $c(\mathrm{~m})$ & 0.005 & 0.027 & 5.40 & 13.22 \\
Amplitude ratio $b / a$ & 0.11 & 0.16 & & \\
\hline
\end{tabular}

constituent is amplified in the bay. Using the data in Table 1, the amplification is by a factor of $1.27,1.81$, and 5.40 for the semi-, quarter, and sixth-diurnal tides respectively. The figures for the semi- and quarter-diurnal tides are broadly in line with the theoretical estimate given above, but the amplification of the sixth-diurnal tide is less than half that of the theoretical value, we think as a result of friction acting on this small higher frequency oscillation in the presence of larger tidal constituents. Note also that the amplitude of the sixthdiurnal tide at the mouth is very small, less than $1 \mathrm{~cm}$.

A technique which is useful in the study of double tides is to select an individual tidal cycle and analyze it for the amplitude and phase of semi-diurnal and higher harmonics for that particular cycle using Fourier analysis (Airy 1843; Doodson and Warburg 1941; Godin 1993; Bowers et al. 2013). The amplitude and phases which result will change from one tidal cycle to another and so are not the same as the tidal constants shown in Table 1, which can be regarded as average values over a long time scale. Harmonics fitted to a single tidal cycle in this way are called ' $D$ ' components (Pugh 1987); for example, the semi-diurnal curve with period $12.4 \mathrm{~h}$ is the D2 component, the quarter-diurnal curve, the D4 component, and so on.

The result of this analysis for a single tidal cycle starting at high water on the 25 February 2015 is shown in Fig. 4. The flattening of the tidal curve at Newport in this cycle is produced by a relatively large D4 component which has a maximum shortly after the low tide in the D2 component (Fig. 4a). For this cycle, the ratio, $b / a$, of the amplitudes of D4 and D2 at Newport is 0.298 (Table 2) which is greater than the critical value of 0.25 needed for the production of a double low water when the phase is optimal. No clear double low water is seen at Newport on this occasion, though, because the phasing is not quite optimal: the maximum in D4 in this case is about 30 min after the minimum in D2.

At Providence (Fig. 4b), the D4 component of the tide has been amplified relative to $\mathrm{D} 2$ and $b / a$ has increased to 0.470 (Table 2). The D4 component of the tide is now nearly half the size of the D2 component and, as a result a clear double low tide is produced at Providence.

Applying this analysis to all days from the first 6 months of 2015 (a total of 336 tidal cycles; Fig. 5 and Table 3) confirms that $b / a$ is increased from the mouth to the head of the bay by $55 \%$ on average (somewhat less than the theoretical $61 \%$ but friction operates in the real bay). Narragansett Bay serves as an amplifier for the $b / a$ ratio. On average, a value of $b / a$ of 0.25 at the mouth will be increased to 0.38 at the head and a flattened tidal curve at low water at the mouth will be turned into a double low water at the head of the bay, as we sketched in Fig. 1. We would therefore expect to see a double high tide at Providence on days when the $b / a$ ratio at Newport equals or exceeds a value of about 0.25 and the quarter diurnal tide has the right phase relative to the semi-diurnal tide.

The ratio of D4 to D2 amplitudes at Newport varies with the spring-neap cycle and is greatest at times of smaller tidal range. This is somewhat surprising (higher harmonics produced by shallow-water effects tend to increase in amplitude more quickly than that of the semi-diurnal tide). The behavior at Newport may have to do with the movement of the semidiurnal amphidrome over the spring-neap cycle (Pugh 1981) or with frictional damping of the higher harmonic outside the bay at higher tidal ranges. It is also the case (although we do not show it for brevity's sake) that the $b / a$ amplification within the bay gets less as the tidal range increases. So, for both reasons, we expect the formation of a double low water to favour neap tides. Fig. 6 shows the semi-diurnal amplitude and the ratio $b / a$ at Newport during the first six months of 2015. Also marked are the occurrences of double low waters at Providence produced by the D4 and D2 tides alone. It is noticeable that these favour neap tides.

Of course, Narragansett Bay is not unique or even special in amplifying D4 more than D2. Any coastal bay with a natural period closer to $6 \mathrm{~h}$ than 12 will do this. What is special about Narragansett Bay is that the $b / a$ ratio at the mouth is unusually large — rising to 0.25 quite frequently and the phase is often just right for producing a flattening at low water. An amplification of $b / a$ within the bay then turns the flattened low water at Newport into a double low water at Providence.

Table 3 includes the value of the coefficient of determination $R^{2}$ for the regression of the amplitude of a tidal constituent (or harmonic) at Providence on the amplitude of the same constituent (or harmonic) at Newport. There is a good correlation for D2 and D4, which is consistent with these constituents being amplified in the bay. The correlation for D6, however, is low. The amplitude of D6 at Newport is very small (Table 3), and the poor correlation between D6 at Providence and Newport suggests that the D6 component of the tide is not behaving in the same way as D2 and D4. The D6 tide at 
Fig. 4 a Analysis of the tidal curve at Newport starting at high water on 25 February 2015. The solid black line is observed water level, the long-dashed line is a fitted semi-diurnal (D2) curve, the short-dash line is the fitted quarter-diurnal (D4) curve and the grey continuous line is the sum of the two fitted curves. b Analysis of the tidal curve at Providence starting at high water on 25 February 2015. The line styles are the same as Fig. 4a. The greater amplification of the D4 harmonic compared to D2 has created the double low water at Providence
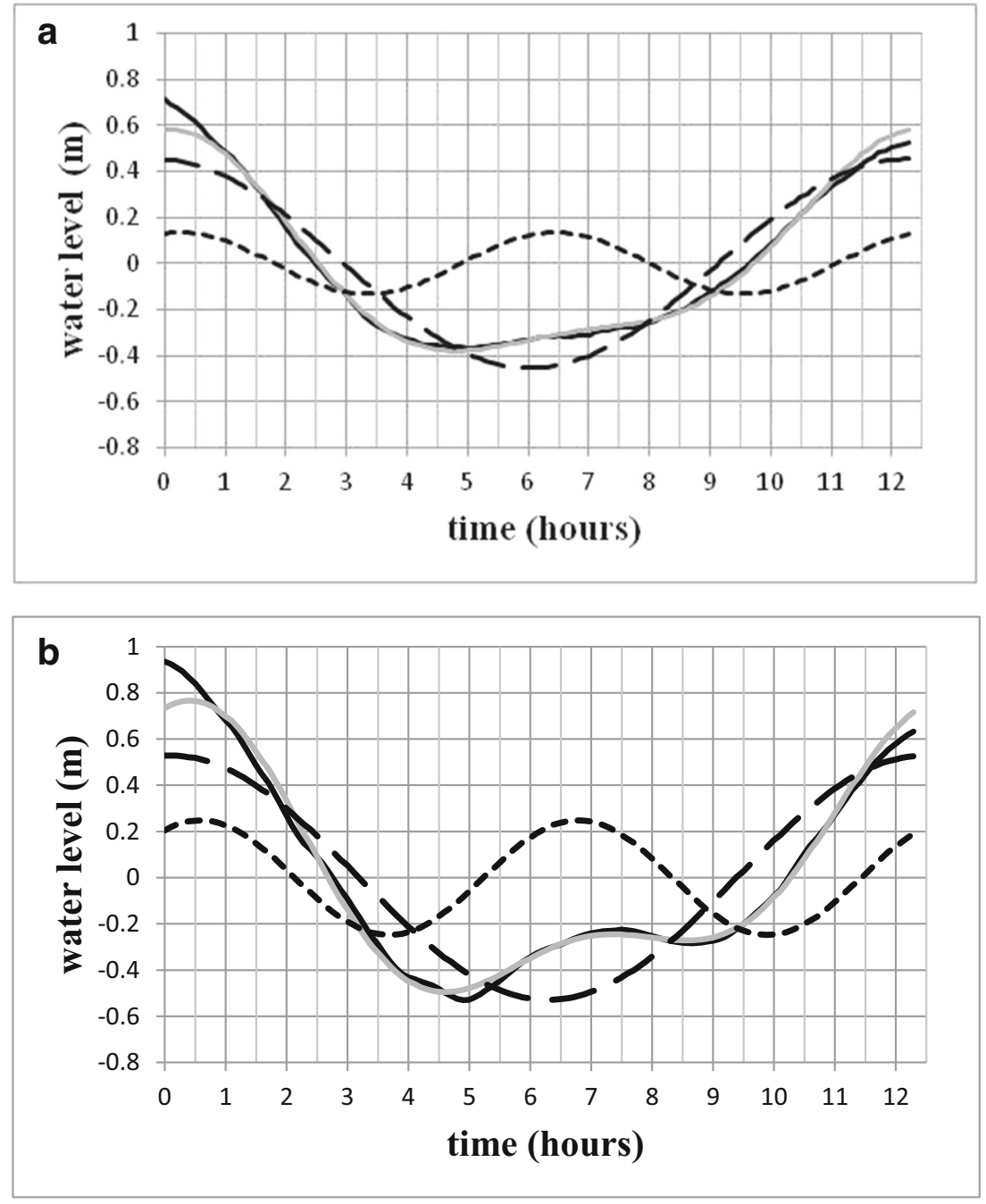

Providence is not just an amplified version of that at Newport. We think that, instead, most of the D6 signal at Providence is produced within the bay. This is something we enlarge on in the next section.

\section{The Importance of Higher Harmonics}

Of the 336 tidal cycles in the first 6 months of 2015, 73 exhibit a double low water at Providence that would satisfy a visual

Table 2 Tidal component amplitudes, for the first tidal cycle (starting at high water) on 25 February 2015

\begin{tabular}{llll}
\hline & Newport & Providence & Observed amplification \\
\hline D2 amplitude, $a(\mathrm{~m})$ & 0.453 & 0.529 & 1.17 \\
D4 amplitude, $b(\mathrm{~m})$ & 0.135 & 0.248 & 1.84 \\
Amplitude ratio $b / a$ & 0.298 & 0.470 & 1.58 \\
\hline
\end{tabular}

inspection. Of these, however, only 13 are produced by D2 and D4 tides alone: that is by the $b / a$ amplification mechanism described in the last section (Fig. 6). In the remaining 60 cases, the relative amplification of the quarter diurnal tide in the gulf serves only to flatten the tidal curve at low water at Providence and then a higher frequency oscillation acts to create a double low water. An example, from the 23 May 2015, is shown in Fig. 7a, in which there is a flattening of the tidal curve at Newport and a double low water at Providence which is not accounted for by D2 and D4 components alone.

For the tidal cycle shown in Fig. $7 \mathrm{a}, b / a$ is 0.218 at Newport and 0.295 at Providence (Table 4). The difference between the observed tide at Providence and the sum of the fitted D2 and D4 curves has the form of a sixth-diurnal oscillation. In the 12.5-h cycle shown in Fig. $7 \mathrm{~b}$, the observed sea level performs three complete oscillations about the fitted curve. The sixth-diurnal (D6) curve that best fits this residual oscillation has been added to this figure. It is quite small in amplitude (only about $10 \mathrm{~cm}$ ) but, superimposed on a flattened tidal curve at low water, it is 
Fig. 5 Ratio (b/a) of amplitudes of D4 and D2 tidal constituents at Providence and Newport. The ratio is amplified within

Narragansett Bay by a factor of 1.55 on average

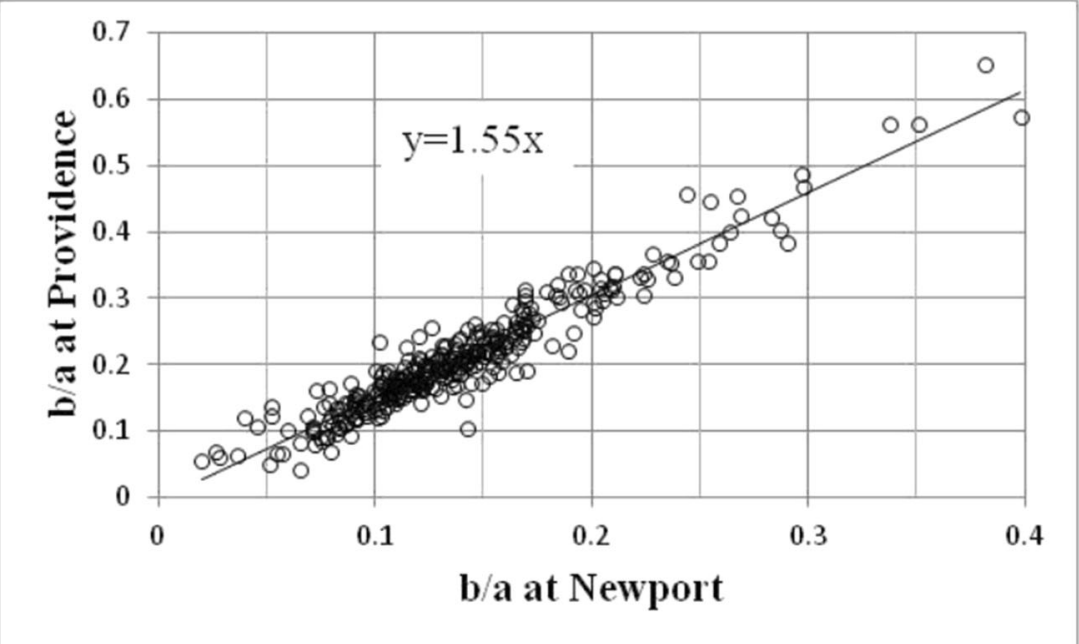

sufficient to produce a dip, a rise and then a second dip - a double low water in the tidal curve at Providence.

There is no significant sixth-diurnal component to the tide at Newport on this day. Figure 7 a shows that the tide at Newport is well represented by D2 and D4 components alone; the amplitude of the fitted D6 component (not shown) is about $4 \mathrm{~mm}$. The D6 oscillation present at Providence has instead been created within the bay. The resonance period of Narragansett Bay is about $4 \mathrm{~h}$-or one sixth of a day-so the bay will oscillate naturally at this period in response to a variety of forcing. Varying wind stress, for example, will produce transient oscillations in the bay with sixth-diurnal period. In addition, the action of quadratic bed friction on the semidiurnal tide (or a mixture of semi- and quarter-diurnal tides) produces a force with sixth-diurnal period (Pugh 1987, page 238). Such a force, acting periodically on the water in the bay, will produce an oscillation in sea level with a period of $4 \mathrm{~h}$.

To summarize matters to this point, we have identified two ways of creating a double low water in Narragansett Bay. The first is by selective amplification of the D4 tide to the point where the sum of D4 and D2 tides at Providence is sufficient to make a double low water. This happens when the $b / a$ ratio at Newport reaches its largest values (about 0.25 ) and is amplified to 0.4 or so at Providence. This mechanism is seen at small neap tides.

In the second mechanism, a lower value of $b / a$ at Newport (of order 0.2 or perhaps a bit less) can be amplified to produce a low tidal curve at Providence with an extended period of flattening. A small high-frequency oscillation added to this will then produce a double-dip low tide. This oscillation is likely to have a period of $4 \mathrm{~h}$, since that is the resonant period of the bay, and it can have a variety of causes.

Spectral analysis of a 3 year record of water level at Providence, kindly made available by A. Valle-Levinson shows the time-variations in the D4 and D6 amplitudes at Providence. The amplitude of the D4 component of the tide generally follows that of D2, increasing and decreasing with the spring-neap cycle. The amplitude of D6 also increases at spring tides (as we would expect if it is created by the friction effect mentioned above), but there are occasional spikes in the amplitude of D6 when the tide is small. Our tentative interpretation of these observations is that the sixth-diurnal oscillation in Narragansett Bay is produced within the bay by a mixture of tidal and non-tidal effects. The fact that the natural period of the bay is close to $4 \mathrm{~h}$ means that any small disturbance will produce an oscillation with this period.

\section{A Quantitative Measure of Double Tides}

When studying the conditions under which double low waters form, it is helpful to identify a measure, preferably based on observations, of the presence and strength of the phenomenon. One way to do this is to consider the rate of change of water

Table 3 Mean tidal component amplitudes, January-June 2015

\begin{tabular}{lllll}
\hline & Newport & Providence & Observed amplification & $R^{2}$ for regression of Providence on Newport \\
\hline D2 amplitude, $a(\mathrm{~m})$ & 0.529 & 0.629 & 1.19 & 0.99 \\
D4 amplitude, $b(\mathrm{~m})$ & 0.070 & 0.125 & 1.79 & 0.88 \\
D6 amplitude, $c(\mathrm{~m})$ & 0.013 & 0.045 & 3.46 & 0.17 \\
Amplitude ratio $b / a$ & 0.134 & 0.208 & & \\
\hline
\end{tabular}


Fig. 6 Semi-diurnal tidal amplitude (labeled $a$ ) and ratio of quarter- to semi-diurnal amplitudes $(b / a)$ at Newport during the first half of 2015. The black points show the occurrences of double low tides at Providence produced by D4 and D2 tides alone. They favour neap tides

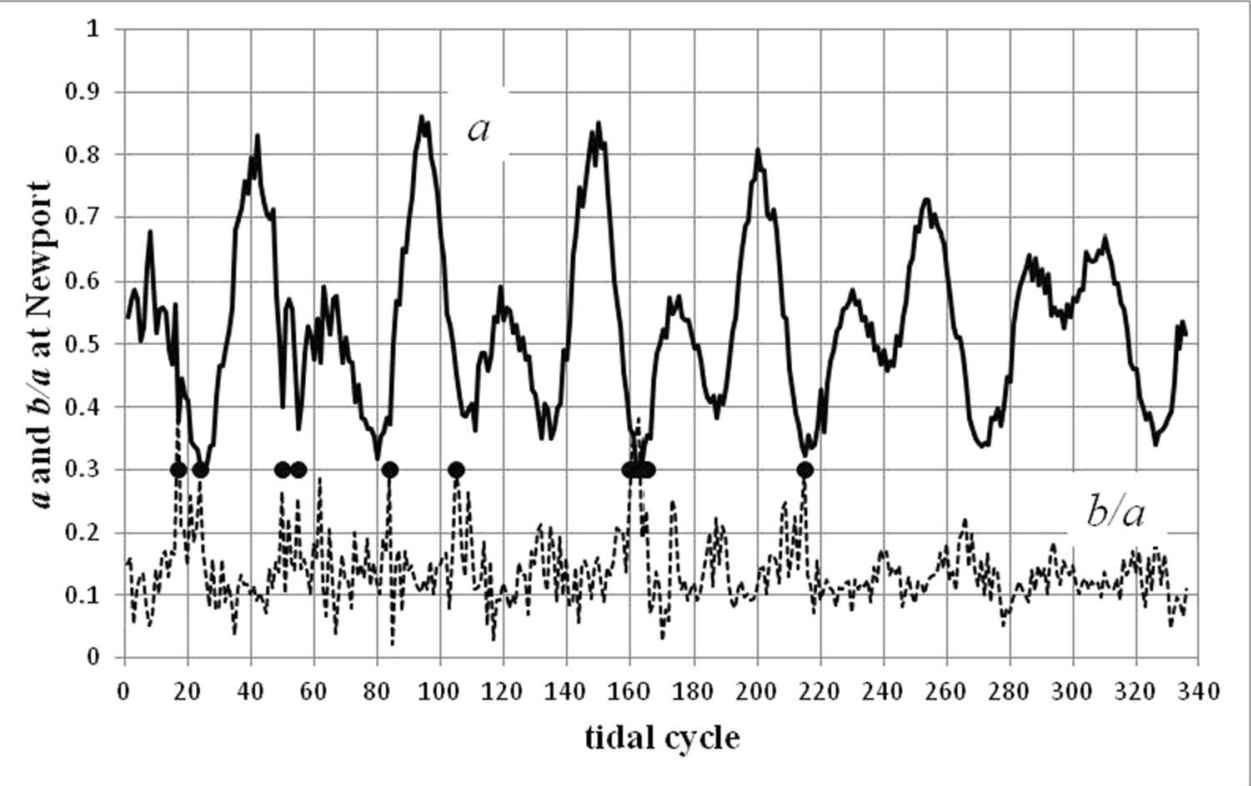

Fig. 7 a Tidal curve for a single tidal cycle starting at high water at Newport on 23 May 2015. The black line is the observed tide and the grey line the sum of fitted D2 and D4 components. b A double low water at Providence for the tidal cycle on 23 May 2015, in which the presence of a sixthdiurnal tide is an essential ingredient. The continuous black curve is the observed sea level, and the continuous grey curve shows the sum of D2 and D4 harmonics, which produce a flattened tidal curve for a period of over $3 \mathrm{~h}$ at low water. The dashed curve is the sixth-diurnal D6 harmonic fitted to the difference between the black and grey curves
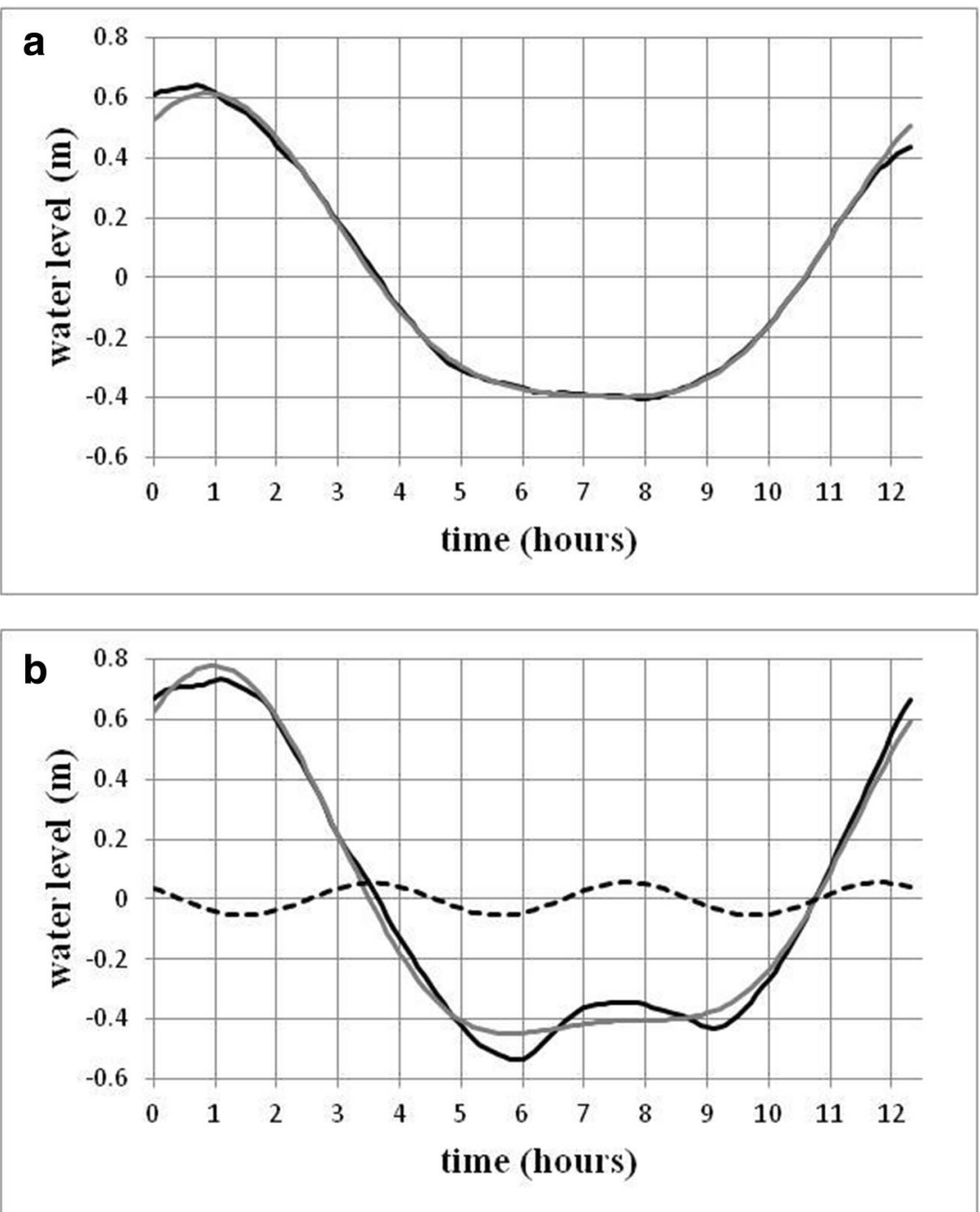
Table 4 Tidal component amplitudes for a single tidal cycle on 23 May 2015

\begin{tabular}{llll}
\hline & Newport & Providence & Observed amplification \\
\hline D2 amplitude, $a(\mathrm{~m})$ & 0.505 & 0.563 & 1.11 \\
D4 amplitude, $b(\mathrm{~m})$ & 0.110 & 0.166 & 1.51 \\
Amplitude ratio $b / a$ & 0.218 & 0.295 & 1.35 \\
\hline
\end{tabular}

level, $d \eta / d t$, for a period after the first (or only) low tide and before the subsequent high water: that is during the rising tide (Fig. 8). In the case of a single low tide, $d \eta / d t$ will always be positive during this period. If there is a stand in the water level after low water, $d \eta / d t$ will equal to 0 at this point. If there is a second low water after the first, then $d \eta / d t$ will become negative just before this second low water occurs.

To establish the presence of a second low water, we therefore determine the minimum value of $d \eta / d t$ during a period between $t_{1}$ and $t_{2}$ hours after the first (or only) low water. We define a quantity $M$ which is the value of this minimum differential, normalized by the amplitude of the $\mathrm{D} 2$ tide, that is

$M=-\frac{1}{a} \min \left(\frac{d \eta}{d t}\right)_{t 1}^{t 2}$

The negative sign is inserted for convenience: when a double low water is present and so the differential becomes negative, then $M>0$. The more pronounced the double low water, the more negative the gradient becomes, resulting in a larger (positive) value of $M$. In choosing values of $t_{1}$ and $t_{2}$, we want to start after the time of the first low tide (when the gradient will be zero by definition) and to finish at a time which is after a possible second low water but is before the subsequent high water. Values of $t_{1}=0.5 \mathrm{~h}$ and $t_{2}=4 \mathrm{~h}$ were used in the calculation of $M$ and the results are expressed in units of hours ${ }^{-1}$. To give a sense of the magnitude of $M$, the values at
Providence on the 25 February and 23 May 2015 (the days of the double low waters illustrated in Figs. $4 b$ and $7 b$ ) are 0.134 and $0.145 \mathrm{~h}^{-1}$, respectively.

We have calculated the value of $M$ at Providence for all tidal cycles in the first 6 months of 2015 and tested its dependence on the ratio $b / a$ of quarter-to semi-diurnal tides at Newport and the phase (relative to D2) of the D4 harmonic at Newport. On average, $M$ becomes positive and a double low water is seen at Providence when $b / a$ at Newport reaches a value of 0.19 (Fig. 9). However, there is a lot of scatter in this plot and positive values of $M$ are seen at much smaller values of $b / a$ (and vice versa).

Some of this scatter is explained by the phasing of the D2 and D4 tides at Newport. The phase difference $\varnothing$ is defined here as the delay, in hours, between low water in the D2 tide and the following high water in the D4 tide (both at Newport; $\varnothing$ is negative if the high in D4 occurs before the low in D2 and positive in the more usual case of the high in $\mathrm{D} 4$ following the low in D2). A phase difference of 0 is optimal for the production of double low waters. Multiple regression of $M$ at Providence on $b / a$ and phase $\varnothing$ at Newport gives the result

$M_{P}=-0.205+1.52(b / a)_{N}-0.126 \varnothing$

In which the subscripts $\mathrm{P}$ and $\mathrm{N}$ refer to Providence and Newport respectively. Equation 3 explains $50 \%$ of the variance in $M$. Fig. 9 shows how $M$ increases with the value of $b / a$ at Newport and decreases as the phase difference $\varnothing$ moves away from zero. When the D4 high water at Newport coincides exactly with the low water in the D2 tide, $\varnothing=0$ and, according to Eq. 3, a double low water is possible in the gulf when $b / a$ at Newport exceeds a value of $0.205 / 1.52$ or 0.14 . The data in Fig. 9 suggests that it is possible for $M_{P}$ to exceed 0 at values of $b / a$ at Newport as small as this.

To summarize matters to this point, a double low water at Providence can be produced by the amplification of the ratio $b / a$ of the amplitudes of quarter and semi-diurnal tides in
Fig. 8 The presence and strength of a double low water can be quantified by considering the minimum value of the rate of change of water level with time $(\mathrm{d} / \mathrm{dt})$ over a period from shortly after the first low water $\left(t_{1}\right)$ up to a time $\left(t_{2}\right)$ before the subsequent high water. If $\mathrm{d} \eta / \mathrm{dt}$ goes negative between these times it indicates the presence of a second low water

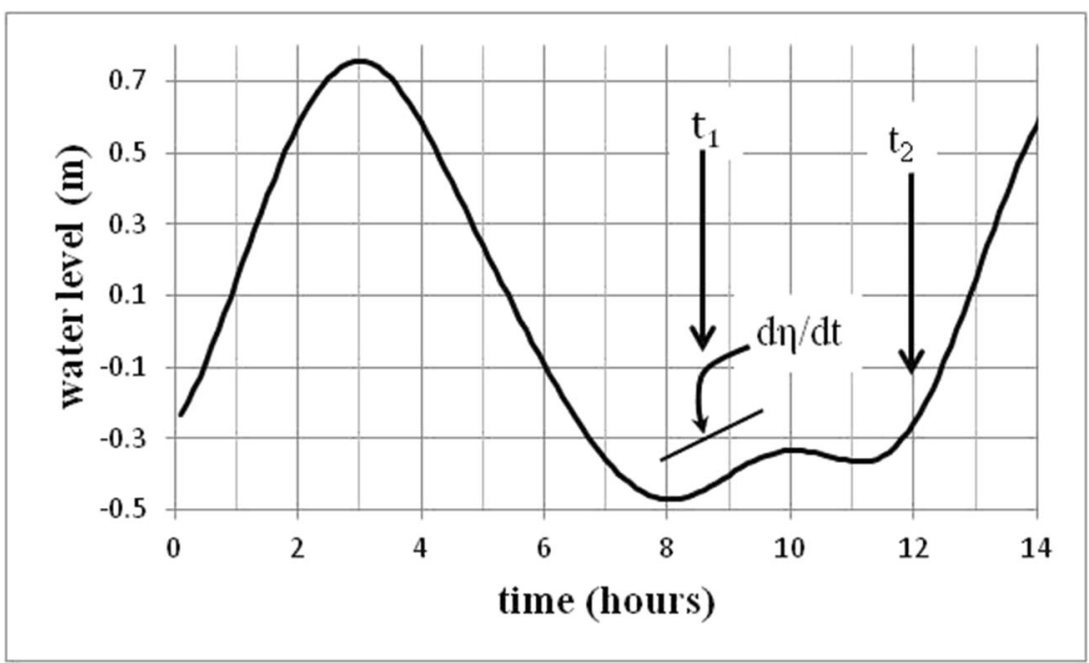


Fig. 9 a The parameter $M$ (Eq. 2 in text) for Providence plotted against the ratio $b / a$ at Newport. A value of $M$ greater than or equal to 0 indicates the presence of a double low water at Providence. b $M$ at Providence plotted against the phase difference of D2 and D4 tides at Newport. A phase difference of 0 is optimal for the production of double low waters. The phase difference is the time delay in the high water in D4 after the low water in D2
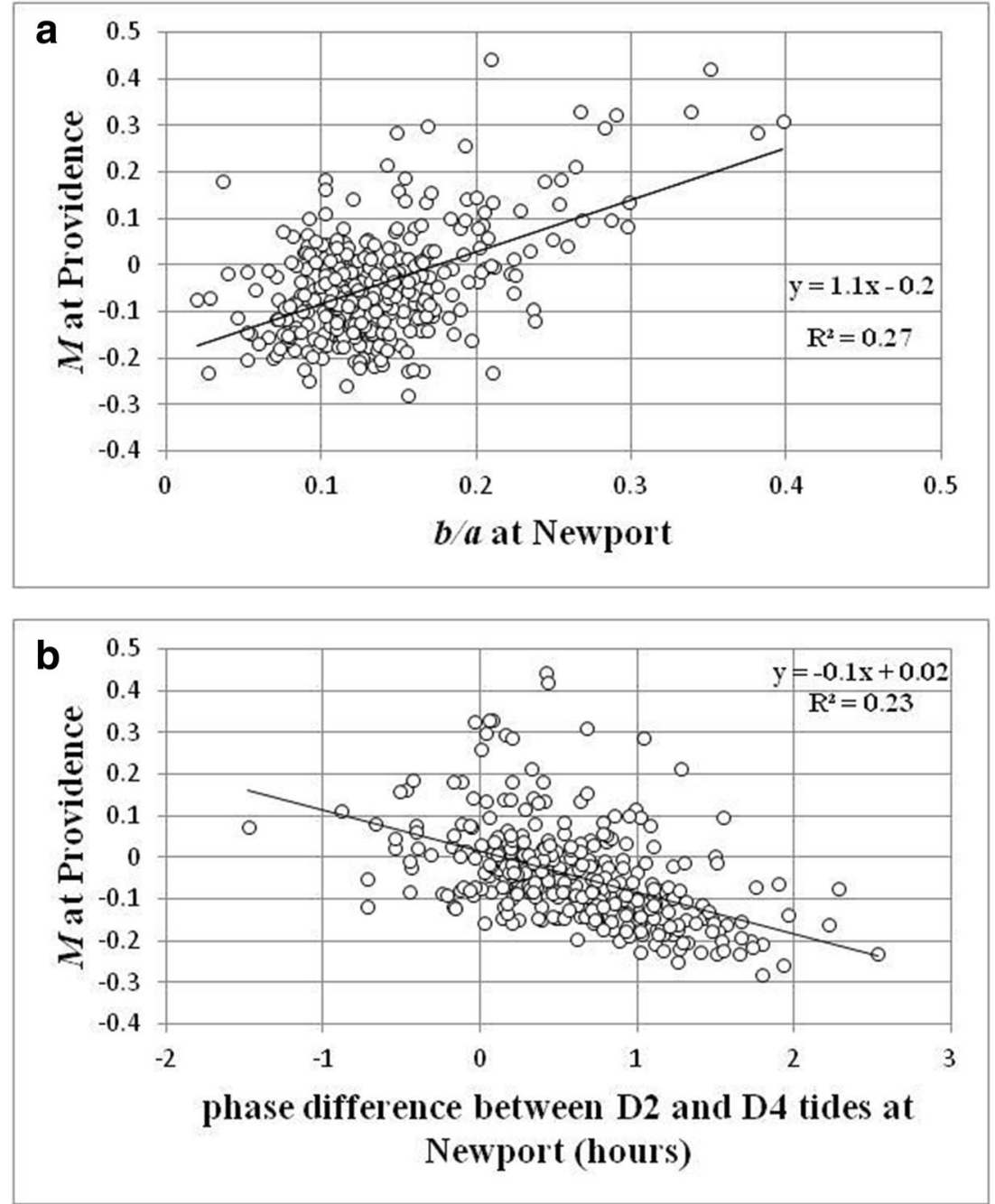

Narragansett Bay. When this happens, a value of $b / a$ of about 0.25 at Newport is amplified to a value of about 0.4 at Providence. A flattened low-tide curve at Newport then becomes a clear double low water at Providence. Alternatively, an oscillation with a period of $4 \mathrm{~h}$ or so (the resonant period of the bay) can create the double low water at Providence. In this case, a lower value of $b / a$ at Newport (as low as about 0.14 ) produces a flattened low tide at Providence and the 6th-diurnal oscillation, acting on the flattened low tide, produces the double low water seen at Providence.

\section{Discussion}

The phenomenon of double high and double low waters in the semi-diurnal tide is included, mostly as a curiosity, in several classic text books on tides. The common explanation offered is that a double tide is created by the addition of higher harmonics to the main tide. This provides a mathematical model, but it leaves a physical explanation wanting. How is the higher harmonic created with the right amplitude and phase to produce the double tide? As an illustration of the limitation of a purely mathematical description, the double low water at Providence is not always predicted by the mathematical model. The NOAA tidal analysis for Providence correctly predicts the double low water on 25 February 2015 shown in this paper but not the one on the 23rd of May in that year. There are not enough harmonics in the analysis to allow for the variation in amplitude of the quarter- and sixth-diurnal tides in Narragansett Bay.

Special conditions are needed for the creation of a double high- or low-water in the semi-diurnal tide. In the case of Narragansett Bay, three features contribute to the production of the double low water. The first is the unusually large quarterdiurnal tide at the mouth. The amplitude of this component regularly rises to $25 \%$ (or more) of that of the semi-diurnal tide at the mouth and it has the right phase for the production of double low waters. We have not seen a double low water at the mouth of the bay in the data examined for this paper, but there is often a flattening of the low water curve there which is the trigger needed 
to create the double low water at Providence. Secondly, Narragansett Bay amplifies the quarter-diurnal tide to a greater extent than the semi-diurnal tide. Thirdly, the natural period of the bay is about $4 \mathrm{~h}$, or one-sixth of a day. Motions which have this period, created for example by the action of quadratic friction on the semi-diurnal tide or by wind-driven seiches, are enhanced within the bay. Occasionally, a double low water is created at Providence by the first two of these features alone, but more, commonly, all three are needed. It is surprising how small an oscillation, added to a flattened tidal curve at low water, can produce a double low water that satisfies a visual inspection.

We have examined the relationship between the occurrence of double low waters in Narragansett Bay and the wind record. Wind strength and direction data are available from NOAA. Some of the double low waters at Providence are associated with a period of strong winds, or a sudden change in wind strength, conditions that we can anticipate would produce a seiche in the bay. However, there are many occasions when the wind is strong and variable and there is no evidence of a double low water. Conversely, there are double low waters when the wind is not doing anything special. The result of this test is therefore inconclusive. We cannot at present offer a clear mechanism, always applicable, for the production of the D6 oscillation at Providence.

The amplification of $b / a$ in the bay, however, is an unambiguous physical mechanism and certainly works to produce a double low water on its own some of the time (and, augmented by a higher frequency oscillation, all of the time). It would be interesting to know if the selective amplification of tidal harmonics in a coastal embayment produces double high-or low-waters in other locations. It is possible that the mechanism contributes to the formation of the double high water at Southampton, for example, which lies at the head of a coastal inlet (Southampton Water). In the open ocean, it is possible to look for the conditions under which double tides might form using tidal models informed by satellite altimetry, but this method cannot be applied to small coastal bays. Instead, it will be necessary to analyze observations of water level. The quantitative test for a double tide (Eq. 2) proposed here, will help to speed up this analysis.

Acknowledgements The authors are grateful to the Professor Wyn Humphries Davis fund, Bangor University, for enabling DGB to visit JMB at the Virginia Institute of Marine Science in December 2015, when this work was carried out. This paper could not have been written without the access to data provided by the NOAA tides and currents website https://tidesandcurrents.noaa.gov/. The paper greatly benefitted from reviews by Professor Phil Woodworth and an anonymous referee and insight (and analysis) provided by the editor, A.E.Valle-Levinson.
Open Access This article is licensed under a Creative Commons Attribution 4.0 International License, which permits use, sharing, adaptation, distribution and reproduction in any medium or format, as long as you give appropriate credit to the original author(s) and the source, provide a link to the Creative Commons licence, and indicate if changes were made. The images or other third party material in this article are included in the article's Creative Commons licence, unless indicated otherwise in a credit line to the material. If material is not included in the article's Creative Commons licence and your intended use is not permitted by statutory regulation or exceeds the permitted use, you will need to obtain permission directly from the copyright holder. To view a copy of this licence, visit http://creativecommons.org/licenses/by/4.0/.

\section{References}

Airy, G.B. 1843. On the Laws of individual tides at Southampton and at Ipswich. Philosophical Transactions of the Royal Society of London 133: 45-54.

Bowers, D.G., R.G.M. Macdonald, D. McKee, W.A.M. Nimmo-Smith, and G.W. Graham. 2013. On the formation of tide-produced seiches and double high waters in coastal seas. Estuarine, Coastal and Shelf Science 134: 108-116.

Byrne, H., M. Green, and D. Bowers. 2017. The double high tide at port Ellen: Doodson's criterion revisited. Ocean Science 13 (4): 599 607.

Doodson, A.T., and H.D. Warburg. 1941. Admiralty manual of tides. London: His Majesty's Stationery Office.

Friedrichs, C.T. 2010. Barotropic tides in channelised estuaries. In Contemporary issues in estuarine physics, ed. A. Valle-Levinson. UK: Cambridge University Press.

Godin, G. 1993. An investigation of the phenomenon of double high water or double low water at some harbours. Deutsche Hydrographische Zeitschrift 45 (2): 87-106.

Gordon, R.B., and M.L. Spaulding. 1987. Numerical simulations of the tidal and wind-driven circulation of Narragansett Bay. Estuarine, Coastal and Shelf Science 24 (5): 611-636.

Harris, R.A. (1907) Report of the superintendent of the US coast and geodetic survey, part 5 .

Hicks, S.D. 1959. The physical oceanography of Narragansett Bay. Limnology and Oceanography 4 (3): 316-327.

Prandle, D. 1991. chapter 7 in tidal hydrodynamics. In Tides in estuaries and embayments (review), ed. B.B. Parker. New York: John Wiley and Sons.

Pugh, D.T. 1981. Tidal amphidrome movement and energy dissipation in the Irish Sea. Geophysical Journal of the Royal Astronomical Society 67 (2): 515-527.

Pugh, D.T. 1987. Tides, surges and mean sea level. Chichester: John Wiley and Sons.

Redfield, A.C. (1980) The tides of New England and New York. Woods Hole Oceanographic Institution.

Simpson, J.H. and J. Sharples (2012) Physical and biological oceanography of shelf seas. Cambridge University Press.

Taylor, G.I. 1921. Tidal oscillations in gulfs and rectangular basins. Proceedings of the London Mathematical Society 20: 148-181.

Woodworth, P.L. 2017. Differences between mean tide level and mean sea level. Journal of Geodesy 91 (1): 69-90. https://doi.org/10.1007/ s00190-016-0938-1. 